\title{
Protecting The Supply Chain: Differentiating Large And Small Suppliers
}

Harlan Platt, Northeastern University, USA

Marjorie Platt, Northeastern University, USA

\begin{abstract}
This paper recounts the history of early warning failure models and then adds to that literature by evaluating the proposition that all suppliers can be treated similarly when evaluating failure tendencies. The work is performed for the automobile supplier industry because that industry has a long and complex supply chain structure and because we have a history of working with major automotive OEMs to protect their supply chain. The project benefited from the support and cooperation of BBK Ltd. the largest turnaround firm worldwide engaged by the automobile sector. In contrast to previous work which utilized a single predictive model to indicate the likelihood that a supplier company was in distress, our effort tested the idea that large and small automobile suppliers face different exigencies and therefore require separate predictive models. The paper concludes by identifying the key factors to consider when reviewing the health of automobile suppliers.
\end{abstract}

Keywords: failure; early warning; supply chain protection; automobile supplier; automobile OEM

\section{INTRODUCTION}

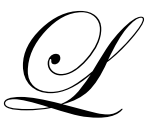

arge manufacturing companies are critically dependent on their suppliers. Nowhere is this reliance more acute than in the automobile industry. Companies such as General Motors or Toyota rely on 3,000 or more suppliers to design, assemble, and deliver components ranging from dashboards to door handles from tires to software. Many supplier relationships are sole sourced by OEMs as a method of obtaining the best possible price, fastest delivery, and overall highest responsiveness to the manufacturer's needs. While this symbiotic relationship has many advantages to the purchaser it creates a major supply chain failure risk. For example, General Motors was recently forced to shut down more than 30 vehicle and component plants and idle 17,000 workers as a result of a strike at American Axle \& Manufacturing Inc. (Jeff Bennett, Wall Street Journal, March 29, 2008, "GM Is Hit Hard by Parts Strike," page A10) with Wall Street warning that the strike will take a toll on profits [General Motors and its other suppliers]. Similar dramatic effects can arise from breaches of the supply chain caused by financial weakness.

To avoid unexpected supply chain disruptions, OEM automobile companies and their purchasing departments keep a sharp eye on the financial health and well being of suppliers. A few manufacturers rely on bond rating agencies and other heuristically based expert systems for alerts indicating that suppliers are in danger of failing. Other companies utilize statistically based early warning models that bifurcate suppliers into those with a high probability of remaining financially healthy and thus supply contracted parts in a timely basis and those not likely to deliver products or services in a reliable fashion, default on their obligations, or go bankrupt. This paper reports on one such statistical model developed by an academic team with the business guidance of a consulting group that has a long history of involvement with automobile OEMs.

Approximately seven years ago this same group of researchers created its first early warning model for the automobile industry, (Platt and Platt, 2002). That model, which was built using data covering the mid 1990s, was subsequently used extensively by the industry. A single model was developed for all auto suppliers regardless of their size. Over time as the model was employed by OEMs, financial institutions, and other related companies it became apparent that its success rate was asymmetric with the greatest success occurring with larger firms. It seems 
that the health of small firms was more difficult to judge with the original model. This paper discusses a second round of model building that improved model performance by accounting for supplier size.

The development of early warning systems is not a new phenomenon. The earliest efforts occurred in the late 1960s and were directed at predicting which companies were likely to go bankrupt. The breakthrough work was conducted by Beaver (1966) who performed a univariate analysis and then later by Altman (1968). Since then other researchers have made statistical contributions (Palepu, 1986), considered the impact of industry on the failure process (Lev, 1969), and more recently have studied not failure but financial distress (Platt and Platt, 2002). This final paper was the first to directly address the supply chain viability and it provided a basis for early intervention at automotive supply companies to ameliorate incipient problems before they resulted in total failure.

\section{THE NATURE OF THE PROBLEM}

OEM automobile manufacturers depend heavily on reliable delivery of critical components from their suppliers. With the industry's adoption of just-in time-inventory methods, failure to supply needed components by any supplier can quickly shut down an entire production line, if not an entire company. For that reason, the concern amongst OEMs is not bankruptcy by their suppliers but an earlier phenomenon known as financial distress. Financial distress is not a well defined construct. Unlike bankruptcy which occurs when a company files a document in a Federal Bankruptcy Court, financial distress arises from a large number of causes but always results in a weakened though still functioning company.

The vast majority of research in this area has examined bankrupt companies and sought to explain the causes of bankruptcy. As mentioned above, OEMs are not really interested in bankruptcy prediction since they want to preserve their supplier relationship. Financial distress research is generally complicated by the question of which companies are financially distressed and which are healthy. BBK Ltd with some assistance obtained from OEMs is a remarkable source of information as to which auto suppliers are healthy and which are financially distressed. Our original examination of auto suppliers (Platt and Platt, 2002) was one of the initial studies of financial distress. For that project, BBK Ltd took charge of creating a sample of auto supply companies bifurcated into financially distressed and healthy groups.

The issue of how to separate the sample into firms that are financially distressed and those that are not is critical to any effort to model the likelihood of financial distress. Prior studies have used both single indicators (reductions in employment, net income loss, or ending of dividends) and multiple indicators (Platt \& Platt, 2002) to bifurcate samples into distressed and non-distressed groups. While Platt \& Platt (2002) offer a compelling argument as to why multiple indicators would be preferred to single indicators, a substantial amount of data are required to do so. At this point, there is no consensus in the literature as to the best categorization scheme. As described below, the current effort combined an assessment from multiple indicators with the views of industry experts.

Again, this study seeks to assess size effects in the prediction of financial distress in the automotive supply chain. Size may simply affect the constant of a linear equation or it may affect the estimated coefficients as well. Because prior observations have suggested that, after many years of use, a model used to predict financial distress in the automotive supply chain was more successful for larger firms than smaller firms, we want to directly test the assumption that there is no difference in model components between large and small automotive suppliers.

\section{METHODOLOGY}

\section{Sample Data and Variables Used in the Analysis}

The vast majority of automobile suppliers are privately held companies. The COMPUSTAT database, for example, only contains 69 public companies in the 3714 SIC or the 336211 - 336399 NAISC (auto supplier) codes. Of these 69 listed firms, 48 had sufficient data available during the sample period, 2005 -- 2006. Fortunately, BBK Ltd. provided us with access to their data base of private companies. With this support a larger database of 106 companies was assembled including 48 public and 58 private companies. The data were limited to the period between 2005 and 2006 as a way to circumvent unequal real values issues (Platt, Platt and Pedersen, 1994). 
Auto suppliers include both domestic and international firms. Global variations in accounting rules, labor legislation, union participation, capital availability, etc. means that international companies operate under different conditions from those in the US. Consequently, OEM's prefer to test foreign suppliers for financial distress with specific national or continental early warning models. Our data is therefore exclusively comprised of US firms.

\section{Dependent Variable: Financial Condition Group}

As discussed above, there have been several approaches taken in past studies to separate samples into distressed and non-distressed firms. For this effort at building a financial distress early warning model of the auto supply industry, we triangulated the problem using subjective decisions and objective measures to separate the sample into financially distressed and non-distressed groups. In addition to relying on the experts at BBK Ltd. we reviewed data (none of which was later used in the model building effort) thought to identify weaker companies. Our analytical test considered a company's return on assets (ROA) and its auditor's going concern opinion (a qualitative variable). Nearly $95 \%$ of the two bifurcations of the sample, from the two teams, were identical. Disagreements were resolved by continued discussion between the teams until a consensus emerged.

Using this approach, the financially distressed group was comprised of $61 \%$ public and $39 \%$ private companies. Similarly, the non-distressed group had $60 \%$ public and $40 \%$ private companies.

\section{Independent Variables}

Financial statement data were obtained from COMPUSTAT for public firms and from BBK Ltd's files for private firms. A small minority of BBK Ltd's data was unaudited, but in those cases the information was carefully reviewed in consultation with BBK Ltd. Financial statement data were obtained for the year prior to the onset of financial distress or for an equivalent time period for the healthy firms in the sample.

Table 1 contains a listing of the individual financial items that were obtained for each company in the sample. The table also details the variety of financial ratios that were created from the individual variables to measure concepts within the five main categories of corporate information: profitability, liquidity, operational efficiency, leverage and growth. As can be seen in Table 1, the raw data that were obtained were those typically reported on financial statements.

A typical OEM has thousands of suppliers. The diversity among auto suppliers is extraordinary with some having annual net sales as small as $\$ 20$ million while others are mega businesses whose sales exceeding $\$ 20$ billion. Table 2 below illustrates this point by comparing mean and median values for net sales, net income, and total assets for small (less than $\$ 100$ million in annual net sales) and large (larger than $\$ 100$ million in annual net sales) companies. The consulting firm guided our decision on where to break the size categories. Larger auto suppliers are over 150 times larger on average than small companies based on sales, and 140 times larger based on total assets.

The general approach to deal with extreme size differences between sample companies is to convert data into ratios using net sales or total assets as the equilibrating numeraire. Underlying this approach is the belief that after conversion to ratios, differences between large and small companies are inconsequential. Generally researchers accept the truth of this supposition; we chose to verify it. To test the theory, three common financial ratios return on equity (ROE), the current ratio (current assets divided by current liabilities), and the debt ratio (total debt divided by total assets) were calculated for the auto suppliers in our sample. Table 3 presents the average value for these ratios for auto suppliers whose annual net sales exceed $\$ 100$ million and those with annual net sales below $\$ 100$ million. The comparison of means t-test indicates that for all three ratios the differences across the two size ranges are significant at or beyond the .10 level of significance. While it is possible (though not certain) that the same factors affect the onset of corporate distress among large and small companies, the large ratio differences between large and small firms suggests the likely impact of these factors is dissimilar. 
Table 1: Individual Items from Financial Statements and Financial Ratios Used in Modeling

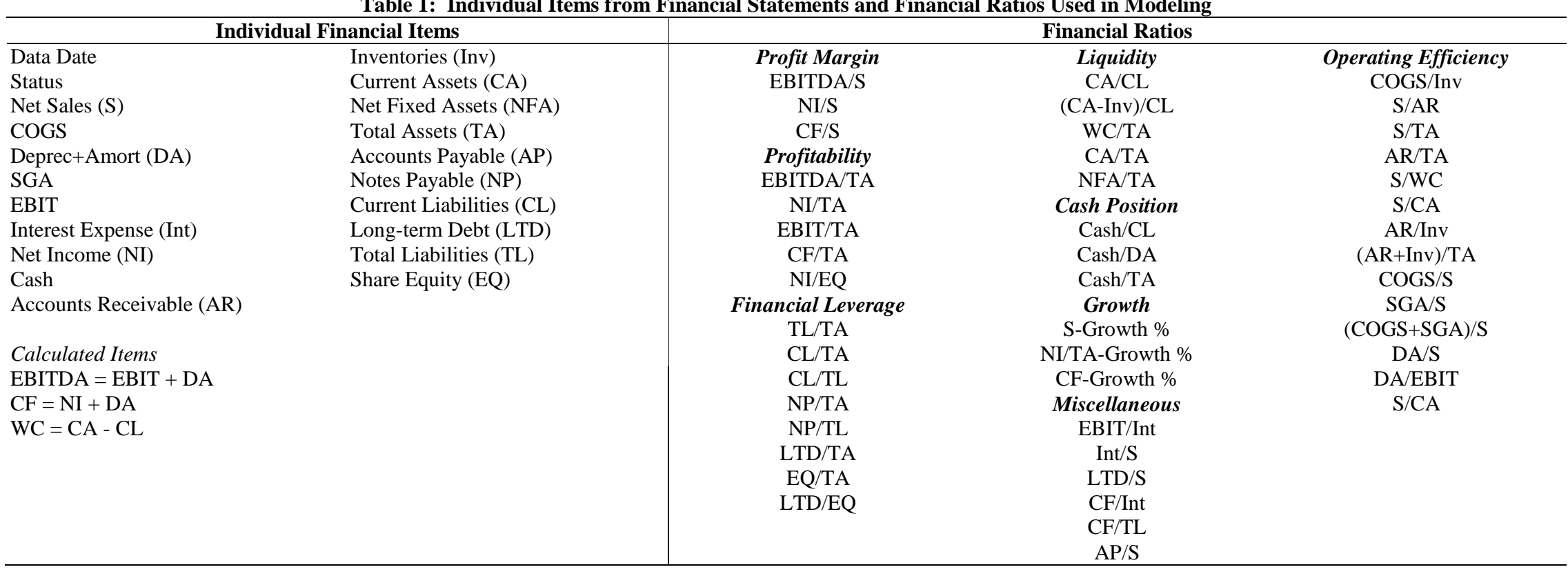


Table 2 (all in \$000s)

Panel A: Sample Means by Firm Size - All Firms

Large $(n=62)$

$\$ 4,361.37$

$(\$ 42.35)$

$\$ 2,840.84$

Small $(n=42)$

$\$ 28.28$

$\$ 0.69$

Net Income

Total Assets

$\$ 20.33$

Panel B: Sample Means by Firm Size - Non-Financially Distressed Firms

\begin{tabular}{lcc}
\hline & Large $(\mathbf{n = 3 2})$ & Small $(\mathbf{n}=\mathbf{2 3})$ \\
\hline Net Sales & $\$ 4,240.27$ & $\$ 234.07$ \\
Net Income & $\$ 101.83$ & $\$ 2.56$ \\
Total Assets & $\$ 2,793.14$ & $\$ 21.85$ \\
\hline
\end{tabular}

Panel C: Sample Means by Firm Size - Financially Distressed Firms

\begin{tabular}{lcc}
\hline & Large $(\mathbf{n}=\mathbf{3 0})$ & Small $(\mathbf{n}=\mathbf{1 9})$ \\
\hline Net Sales & $\$ 4,648.19$ & $\$ 20.97$ \\
Net Income & $(\$ 388.83)$ & $(\$ 1.92)$ \\
Total Assets & $\$ 2,953.82$ & $\$ 18.41$ \\
\hline
\end{tabular}

Table 3 Comparison of Means: Key Financial Ratios by Size for Just Non-Financially Distressed Firms

\begin{tabular}{lccc} 
& Large & Small \\
& $(\mathbf{n = 3 2})$ & $(\mathbf{n = 2 3 )}$ & p-value \\
\hline CA.CL & 2.209 & 1.571 & 0.0509 \\
NI.TA & 0.050 & 0.157 & 0.0006 \\
TD.TA & 0.185 & 0.269 & 0.0593 \\
ROE & 0.092 & 0.507 & 0.0019 \\
\hline
\end{tabular}

Where:

CA.CL $=$ Current Assets/Current Liabilities

NI.TA $\quad=\quad$ Net Income/Total Assets

TD.TA $=$ Total Debt/Total Assets

ROE $\quad=\quad$ Net Income/Shareholders' Equity

TD $\quad=\quad$ Notes Payable + Current Portion of Long-term Debt + Long-term Debt

\section{Model Design and Estimation Method}

Early warning statistical models specify a relationship between causal factors and a qualitative dependent variable that assumes the value of either zero in the case of healthy companies or unity for companies thought to be financially distressed. Perhaps the most common statistical method used in developing these models is logit regression analysis. Among the advantages of logit regression are its statistical powers (Lo, 1986) and its flexibility (McFadden, 1984) which arises in part from its non-linear form. Our model utilizes the logit format.

The typical estimation method to obtain parameter estimates for a logit model is a non-linear maximumlikelihood estimation procedure. The form of the equation is shown below in equation (1).

$$
\boldsymbol{P}_{i}=\frac{1}{\left[1+\exp ^{-\left(\beta_{0}+\beta_{1} X_{i l}+\beta_{2} X_{i 2}+\ldots+\beta_{n} X_{i n}\right)}\right]}
$$


where:

$P_{i}=$ probability of financial distress of the $i^{\text {th }}$ firm,

$X_{i j}=j^{\text {th }}$ variable of the $i^{\text {th }}$ firm, and

$\beta_{\mathrm{j}}=$ estimated coefficient for the $\mathrm{j}^{\text {th }}$ variable.

The modeling process began with the core model specification previously identified by Platt and Platt (2002). Only one of the six independent variables in the original model remained significant with the newer data set. After excluding insignificant variables in the initial set, additional explanatory variables were sought from groups of possible variables in Table 3 that did not have a variable included in the current set. This iterative process expanded the core set of variables when an additional factor yielded a coefficient with the correct sign, statistical significance, and improved classification accuracy (correctly identifying a company as financially distressed or healthy). An additional advantage of this approach is that it minimizes the likelihood of multicollinearity by working through the possible variable list in a systematic fashion and thereby avoiding using two independent variables design to capture similar information. The selection of the final set of financial and operating ratios was based on the statistical significance and direction of estimated parameters and on the model's classification accuracy.

Equation (1) assumes that all companies, in this case auto suppliers, are similar and that a single model and set of parameter estimates adequately represent the industry's financial distress likelihood. However, the data observed above in Tables 2 and 3 demonstrate a disparity between large and small auto supply companies and casts doubt on the appropriateness of a single model for all companies. This issue is discussed below using, for simplicity purposes, a linear depiction of equation (2).

$$
P_{i}=\beta_{0}+\beta_{j} X_{i . j}+\varepsilon
$$

where $X_{i . j}$ represents a vector of variables describing the financial distress condition of all firms in the auto supply industry. This equation represents the null hypothesis that assumes similarity in the financial distress condition of all auto suppliers.

The alternate hypothesis argues that estimates of the probability of financial distress can be improved by accounting for size differences between auto suppliers. The alternate hypothesis is shown in equation (3).

$$
P_{i}=\beta_{0}+\lambda_{0} D_{\text {small }}+\beta_{j} X_{i . j}+\lambda_{j} D_{\text {small }} X_{i, j}+\varepsilon
$$

where $D_{\text {small }}$ is a indicator variable with a value of 0 for large auto supply companies (larger than $\$ 100$ million in annual sales) and a unit value for small companies, $\lambda_{\boldsymbol{0}}$ is the constant term differential for small firms, and $\boldsymbol{\lambda}_{\boldsymbol{j}}$ represents a vector of coefficient estimates derived for interactions between the indicator variable $D_{\text {small }}$ and $\mathrm{X}_{\mathrm{i}, \mathrm{j}}$ the vector of independent variables.

If the estimation process yields a nonzero value for $\lambda_{0}$ which is significantly different than zero then large and small firms require different constant terms in a financial distress model. Similarly, whenever an estimated coefficient in the $\lambda_{j}$ vector is nonzero and significant the independent variable associated with that particular variable has unequal impacts on the probability of financial distress for large and small firms. In the event that both $\lambda_{0}$ and each coefficient in the $\lambda_{j}$ vector is significant there are then two separate models, one for large and one for small firms, which can be represented as in equations (4a) and (4b).

$$
P_{i, \text { small }}=\beta_{\text {small }}+\beta_{j, \text { small }} X_{i . j}+\varepsilon
$$




$$
P_{i, \text { large }}=\beta_{\text {large }}+\beta_{j, \text { large }} X_{i . j}+\varepsilon
$$

The null and alternate hypotheses presented conceptually in equations (2) and (3) are compared using the Chow test (Chow, 1960), which tests whether the coefficients in two linear regression equations are equal for two different sample groups. The null hypothesis tested is essentially: $\lambda_{0}=\lambda_{j}=\boldsymbol{O}$.

The Chow test calculates the following F statistic:

$$
F_{K, n+m-2 K)}=\frac{\left(S S E_{C}-S S E_{\text {small }}-S S E_{\text {large }}\right) / K}{\left(S S E_{\text {small }}+S S E_{\text {large }}\right) /\left(n_{\text {small }}+m_{\text {large }}-2 K\right)}
$$

where:

$\mathrm{SSE}_{\mathrm{C}}=\mathrm{SSE}$ for the equation based on the combined sample, shown in equation (2) with sample size of $\mathrm{n}+\mathrm{m}$

$\mathrm{SSE}_{\text {small }}=\mathrm{SSE}$ for the equation based on the small firms, shown in equation (4a), with sample size of $\mathrm{n}$

$\mathrm{SSE}_{\text {large }}=\mathrm{SSE}$ for the equation based on the large firms, shown in equation (4b), with sample size of $\mathrm{m}$

$\mathrm{K} \quad=$ number of degrees of freedom for the combined model

\section{MODEL RESULTS}

Using the entire sample and the iterative method described above, financial distress was found to be positively related to financial leverage (TD.TA), but negatively related to the EBITDA margin (EBITDA.S), the current ratio (CA.CL), the times interest earned ratio (TIE) and sales turnover (S.TA). Thus, the probability that a company is financially distressed increases with higher financial leverage, but decreases with higher EBITDA margin, current ratio, times interest earned, or sales turnover. The relationship of each of the five independent variables with the likelihood of financial distress is as expected a priori. The final form of the model is shown in Table 4 along with measures of model fit, $\mathrm{R}^{2}$ and classification accuracy as well as the sum of the squared errors. The model fits well, with a $76.3 \% \mathrm{R}^{2}$ and an overall classification rate between the two groups of $90.6 \%$.

Table 4: Logit Regression Financial Distress Model: All Firms

\begin{tabular}{lcc}
\hline Independent Variable & Estimated Regression Coefficient* & p-value \\
\hline Constant & -1.56 & 0.188 \\
EBITDA.S & -18.15 & 0.000 \\
S.TA & -1.25 & 0.001 \\
TD.TA & 3.01 & 0.000 \\
CA.CL & -1.16 & 0.015 \\
TIE & -3.19 & 0.041 \\
Model Fit: & Nagelkerk R2 & \\
\multicolumn{2}{c}{} & \\
\hline Classification Accuracy: & $90.6 \%$ & \\
\hline$\%$ All Firms Correctly Classified & $92.9 \%$ & \\
$\%$ Non-Financially Distressed Firms Correctly Classified & $88.0 \%$ & \\
$\%$ Financially Distressed Firms Correctly Classified
\end{tabular}

*Coefficients are scaled to disguise their true values since they are the property of BBK Ltd.

Where:

EBITDA.S = EBITDA margin $($ EBITDA/sales $)$

S.TA $=$ Sales turnover (sales/total assets)

TD.TA $=$ Financial leverage (total debt/total assets)

CA.CL = Liquidity (current assets/current liabilities)

TIE $=$ Times interest earned $(($ net income + interest expense + taxes $) /$ interest expense $)$ 
Because the automotive OEMs are concerned about size effects, we tested the null hypothesis that firm size does not affect the estimated coefficient values; that is, size has no effect on the prediction of financial distress in the automotive supply chain. Using the Chow test described above, the model containing the five significant independent variables, financial leverage, EBITDA margin, current ratio, and times interest earned and sales turnover, was estimated for the sample of small firms (less than or equal to $\$ 100 \mathrm{M}$ in annual net sales) and for large firms. Table 5 contains the estimated coefficients for these two models along with measures of fit and the sum of squared errors. The Chow test results yielded an $\mathrm{F}_{3,98}=15.05, p<.01$; thus, the null hypothesis of no size effect must be rejected. Alternatively, the small firm and large firm model estimated coefficients shown in Table 5 are significantly different. This result suggests that while the determinants of financial distress have similar relationships to the likelihood of financial distress for the two size groups, the magnitude of the effects differ significantly between small versus large firms. Thus, to predict financial distress among the automotive supply chain, one should use the appropriate model, based on a firm's size.

It should be noted that model fit improves when the sample is bifurcated into large and small firms: the $\mathrm{R}^{2}$ is $85.0 \%$ for small firms and $87.2 \%$ for large firms while the overall classification rate increases to $92.9 \%$ for small firms and $96.8 \%$ for large firms. Therefore, by estimating separate models for large and small firms, alternate coefficients are estimated with improved model fit. Effectively, size-based samples improve the ability to predict financial distress of auto suppliers.

Table 5

Panel A: Logit Regression Financial Distress Model: Small Firms

\begin{tabular}{lcc}
\hline Independent Variable & Estimated Regression Coefficient* & p-value \\
\hline Constant & 0.33 & 0.143 \\
EBITDA.S & -29.73 & 0.018 \\
S.TA & -1.84 & 0.068 \\
TD.TA & 3.32 & 0.065 \\
CA.CL & -1.99 & 0.024 \\
TIE & -2.76 & 0.033 \\
Model Fit: & Nagelkerk R2 & \\
\hline Classification Accuracy: & $95.0 \%$ & \\
\hline \% All Firms Correctly Classified & $95.9 \%$ & \\
\% Non-Financially Distressed Firms Correctly Classified & $89.5 \%$ & \\
\% Financially Distressed Firms Correctly Classified & & \\
\hline
\end{tabular}

*Coefficients are scaled to disguise their true values since they are the property of BBK Ltd.

Panel B: Logit Regression Financial Distress Model: Large Firms

\begin{tabular}{lcc}
\hline Independent Variable & Estimated Regression Coefficient* & p-value \\
\hline Constant & 0.45 & 0.212 \\
EBITDA.S & -52.11 & 0.010 \\
S.TA & -2.42 & 0.083 \\
TD.TA & 10.11 & 0.006 \\
CA.CL & -2.54 & 0.034 \\
TIE & -3.16 & 0.048 \\
Model Fit: & Nagelkerk R2 $=87.2 \%$ & \\
\hline Classification Accuracy: & $96.8 \%$ & \\
\hline \% All Firms Correctly Classified & $96.9 \%$ & \\
\% Non-Financially Distressed Firms Correctly Classified & $96.7 \%$ & \\
\% Financially Distressed Firms Correctly Classified & & \\
*Coefficients are scaled to disguise their true values since they are the property of BBK Ltd.
\end{tabular}

Where:

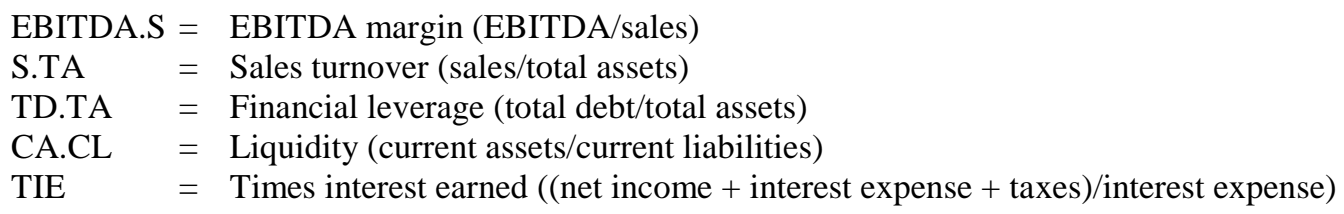


The estimated coefficients of the small firm model, shown in the upper panel of Table 5, and the large firm model, shown in the lower panel of Table 5, have the expected sign. All are significant beyond the .05 level, using a one-tailed test. The $\mathrm{R}^{2}$ values for both models have improved from that found in the combined model shown in Table 4, and the classification accuracy for both models has improved as well. This last point is especially important, since the real test of a prediction model is its ability to correctly classify companies as financially distressed or not. In both models, there is a slightly higher accuracy of predicting non-financially distressed companies. This differential in classification accuracy between non-distressed and distressed firms is typical of these types of models and probably occurs because of the multiplicity of ways that companies depart from normality.

\section{DISCUSSION AND CONCLUSION}

Steps that companies take to protect their supply chain are multifaceted, including a) the sharing of technologies and the making of plant location decisions jointly with suppliers, b) writing contracts which protect suppliers against resource price changes and which provide sole sourcing, and as discussed in this paper c) taking steps to identify and ameliorate troubled suppliers. Trying to fix a broken supplier after it files for bankruptcy court protection is probably too late to resolve financial or operational issues in a timely fashion to ensure the reliable delivery of components through the supply chain and most certainly creates a disruption in short-term deliveries. A better strategy is to build early warning models to identify troubled suppliers possibly even before they are aware of impending problems themselves.

Model builders, such as those who build early warning tools to help companies identify weak links in the supply chain, may rely incorrectly on commonly known but factually inaccurate suppositions. This paper discusses and tests one such supposition that states that the creation of ratios corrects for size differences between large and small firms. A statistical test determined that the underlying concept was not supported by the data. The issue was resolved by developing two models: one each for large and small companies. While financial distress among small and large auto supply companies was found to be related to the same set of variables (financial leverage, EBITDA margin, the current ratio, the times interest earned ratio and sales turnover), estimated coefficients were found to be statistically significantly different between the two types of firms based on size. The models estimated after bifurcating large and small firms not only produced alternate coefficient estimates but produced improved model fit as measured by goodness of fit and more importantly by the models' classification accuracy. Prediction of financial distress among auto suppliers should be improved as a result of this finding.

\section{AUTHOR INFORMATION}

Harlan D. Platt is a Professor of Finance at Northeastern University in Boston. He received his Ph.D. from the University of Michigan and a B.A. from Northwestern University. His principle teaching assignment is a course entitled Strategies for Companies in Crisis. He coordinated all graduate business programs in the college for three years. In addition, he was the Faculty Dean of the Turnaround Management Association, located in Chicago, for ten years. He is the author of eight books and over forty academic articles.

Marjorie B. Platt is Professor and Group Coordinator of Accounting at Northeastern University. She received her Ph.D. from the University of Michigan, B.A. from Northwestern University, and MBA from Babson College. She publishes and consults on the prediction of corporate bankruptcy and financial distress. Also, she examines how managers use financial and non-financial information in decision making, particularly in new product development. She has published over fifty academic articles, most recently in Journal of Product Innovation Management, Advances in Management Accounting, Accounting Horizons, Journal of Business Research, and Journal of Business Finance \& Accounting.

\section{REFERENCES}

1. Altman, E.I. (1968). Financial ratios, discriminant analysis and the prediction of corporate bankruptcy. Journal of Finance, 23, 589-609.

2. Beaver, W. (1966). Financial ratios as predictors of failures. Journal of Accounting Research, 4(Supplement), 71-102. 
3. Chow, G. C. (1960). Tests of equality between sets of coefficients in two linear regressions. Econometrica, 28, 591-605.

4. $\quad$ Dixon, W. J. \& F. J. Massey, Jr. (1969). Introduction to statistical analysis, $3^{\text {rd }}$ edition. New York: McGraw Hill.

5. Hausman, J., H. Ichimura, W. Newey \& J. Powell. (1991). Measurement errors in polynomial regression models. Journal of Econometrics, 50, 271-295.

6. Lachenbruch, P. (1967). An almost unbiased method of obtaining confidence intervals for the probability of misclassification in discriminant analysis, Biometrics 23, 639-645.

7. Lev, B. (1969). Industry averages as targets for financial ratios, Journal of Accounting Research, 7, 290299.

8. Lo, A. (1986). Logit versus discriminant analysis: A specification test and application to corporate bankruptcy. Journal of Econometrics, 31, 151-178.

9. McFadden, D. (1984). Econometric analysis of qualitative response models. In Z. Griliches and M. Intriligator, (Eds.), Handbook of Econometrics, Vol. 2 Amsterdam: North Holland.

10. Palepu, K. (1986). Predicting takeover targets: A methodological and empirical analysis. Journal of Accounting and Economics, 8, 3-35.

11. Platt, H., M. B. Platt \& J. G. Pedersen. (1994). Bankruptcy discrimination with real variables. Journal of Business Finance and Accounting, 21, 491-510.

12. Platt, H. \& M. B. Platt. (2002). Predicting corporate financial distress: Reflections on choice-based sample bias. Journal of Economics and Finance, 26, 184-199 